\title{
TRABALHANDO NÚMEROS E OPERAÇÕES COM ALUNOS DOS ANOS INICIAIS DO ENSINO FUNDAMENTAL SOB A ÓTICA DA RESOLUÇÃO DE PROBLEMAS
}

\author{
WORKING ON NUMBERS AND OPERATIONS WITH STUDENTS OF THE \\ FIRST YEARS OF ELEMENTARY SCHOOL FROM THE PERSPECTIVE OF \\ PROBLEM SOLVING
}

\author{
Manoel dos Santos Costa ${ }^{1}$ \\ Norma Suely Gomes Allevato ${ }^{2}$ \\ Célia Barros Nunes ${ }^{3}$
}

\section{Resumo}

Buscamos no presente artigo explorar alguns aspectos relacionados aos conteúdos referentes ao bloco Números e Operações, apresentado pelos Parâmetros Curriculares Nacionais - PCN (BRASIL, 1997). Fazendo uso da Metodologia de Ensino-Aprendizagem-Avaliação de Matemática através da Resolução de Problemas, trabalhamos conceitos básicos de Aritmética e as primeiras noções de Álgebra nos anos iniciais do Ensino Fundamental, considerando a avaliação como um processo integrado ao ensino e à aprendizagem de Matemática num contexto de trabalho através da resolução de problemas. Os dados aqui descritos e analisados compõem um estudo de natureza qualitativa, que foi realizado com alunos do $5 .^{\circ}$ ano do Ensino Fundamental de uma escola pública estadual na cidade de São Luís/MA, por meio de observação e de análise documental das resoluções dos problemas apresentados pelos alunos. Os resultados mostram que os alunos (re)construíram o conceito de multiplicação e divisão, percebendo a relação existente entre essas operações como operações inversas. Também construíram as primeiras noções de Álgebra (equação), sem utilizarem variáveis como $\mathrm{x}$ e $\mathrm{y}$ usualmente utilizadas pelos professores na apresentação desse conteúdo.

Palavras-chave: Educação Matemática. Números e Operações. Resolução de Problemas.

\footnotetext{
${ }^{1} \mathrm{O}$ autor é doutor em ensino de ciências e matemática pela Universidade Cruzeiro do Sul UNICSUL. atualmente é professor e pesquisador da universidade CEUMA - UNICEUMA, em São Luís/MA. E-mail: manolopromat@hotmail.com

2 A autora é doutora em educação matemática. É Professora, pesquisadora e coordenadora do programa de pós-graduação (mestrado) em ensino de ciências e matemática da Universidade Cruzeiro do Sul - UNICSUL, em São Paulo/SP. E-mail: normallev@gmail.com

${ }^{3}$ A autora é doutora em educação matemática. É professora e pesquisadora Universidade do Estado da Bahia - Campus X. E-mail: celiabns@gmail.com
} 


\section{Abstract}

In the present paper, we seek to explore some aspects of the contents related to Numbers and Operations, presented by "Parâmetros Curriculares Nacionais - PCN" (Brasil, 1997). By making use of the Methodology of Mathematics Teaching-learning-evaluation through Problem Solving, we have worked on basic concepts of Arithmetic and the early notions of Algebra in the first years of Elementary School, considering evaluation as an integrated process to teaching and learning Mathematics in a work context through problem solving. The data reported and analysed here make up a qualitative study involving fifth grade students from a state public school in the city of São Luís/MA, and the instruments were observation and document analysis of problem solving presented by the students. The results show that the students (re)built the concept of multiplication and division and understood the relation between those operations as inverse operations. They also built the early notions of Algebra (equation) without using the variables as $\mathrm{x}$ and $\mathrm{y}$ often used by teachers in presenting such content.

Key-words: Mathematics Education. Numbers and Operations. Problem Solving.

\section{Introdução}

O ensino de Matemática nos anos iniciais do Ensino Fundamental vem sendo questionado por pesquisadores da área (CURI, 2005; COSTA, 2008; PIRES, 2012). A constatação de que a maioria dos alunos desse nivel de ensino considera a Matemática como sendo uma das disciplinas mais dificeis do currículo escolar torna-se preocupante, podendo estar ligada ao fato de que muitos professores deixam "marcas" negativas na vida de seus alunos, praticando metodologias de ensino que dificultam o processo de aprendizagem de conceitos e procedimentos matemáticos, principalmente dos que se referem aos conteúdos envolvendo os números e as operações, desenvolvidos nesse nível de ensino.

Segundo Vygotsky (1987 apud BANDEIRA, 2009), o ensino que inicia com a apresentação de conceitos e procedimentos não tem relevância para o aluno, do ponto de vista da construção de conhecimentos. De acordo com o autor, 
O ensino direto de conceitos é impossivel e infrutífero. Um professor que tenta fazer isso geralmente não obtém qualquer resultado, exceto o verbalismo vazio, uma repetição de palavras pela criança, semelhante à de um papagaio, que simula um conhecimento dos conceitos correspondentes, mas que na realidade oculta um vácuo. (VYGOTSKY, 1987 apud BANDEIRA, 2009, p. 3).

Para alguns pesquisadores (FIORENTINI, 2001; ITACARAMBI, 2010) a Matemática dos anos iniciais ainda é tratada em sala de aula como sendo constituída pelo uso de técnicas operatórias e da simples memorização, com a prática da reprodução, o que não faz sentido aos alunos e, consequentemente, não garante sua aprendizagem. $O$ aluno precisa ser envolvido em atividades matemáticas que lhes permitam a construção de sua aprendizagem de forma significativa, e essa construção deve ser mediada pelo professor que precisa estar "aberto" a mudanças didáticopedagógicas, isto é, à utilização de "novas" metodologias de ensino, de modo que possa construir novos conceitos e procedimentos ligados ao conteúdo em estudo. Tais metodologias devem motivar, também, o professor, com vistas a compreender melhor seu aluno, suas dificuldades e a maneira como constrói sua aprendizagem.

Por isso, no trabalho discutido neste artigo, desenvolvemos atividades (problemas) envolvendo números e operações utilizando a metodologia de ensino-aprendizagem-avaliação de Matemática através da resolução de problemas. Essa metodologia oferece ao professor não somente diversas oportunidades de desafiar seus alunos a encontrar solução para o problema gerador 4 em estudo, como também possibilita ao aluno um envolvimento maior nos modos de pensar e de desenvolver a Matemática que precisa aprender (NUNES, 2014). E, além disso, o processo de construção do conhecimento acontece tanto de forma individual quanto de forma. (ONUCHIC; ALLEVATO, 2009; COSTA; ALLEVATO, 2015).

\footnotetext{
${ }^{4}$ Problema gerador - Problema proposto aos alunos como ponto de partida e orientação para a aprendizagem de novos conceitos e conteúdos matemáticos (ALLEVATO; ONUCHIC, 2014, p. 45).
} 
Organizamos o presente trabalho em quatro seções principais. Iniciamos apresentando os aportes teóricos sobre números e operações e sobre resolução de problemas, seguidos a resolução de problemas como metodologia de ensino-aprendizagem-avaliação, na perspectiva de Allevato e Onuchic (2014). A terceira seção, apresenta do cenário e da metodologia utilizada na pesquisa. Na quarta seção delineamos os problemas geradores, os procedimentos utilizados pelos alunos para solucioná-los e a análise dessas resoluções. Finalizamos apresentando nossas Considerações Finais e as Referências.

\section{Aportes Teóricos: Números e Operações e Resolução de Problemas}

Não é possivel tratarmos de números e operações sem discutir o sistema de numeração que usamos no Brasil, pois sem considerar um sistema de numeração - em nosso caso, o decimal - fica impossível trabalharmos com as quantidades. "O sistema de numeração nos permite registrar as quantidades de maneira mais exata do que [somente pela] percepção e nos lembrarmos dessa quantidade quando precisarmos". (NUNES et al., 2009, p. 33).

Além disso, os sistemas de numeração aumentam nossa capacidade de raciocinar sobre quantidades, indo ao encontro do que é exposto pelos PCN - Parâmetros Curriculares Nacionais em relação ao sistema de numeração no ensino de Matemática do Ensino Fundamental. Segundo o documento, os sistemas de numeração ajudam os alunos a "utilizar a linguagem matemática como meio para produzir, expressar e comunicar suas ideias [...]”. (BRASIL, 1997, p. 9).

Sendo assim, buscamos aportes teóricos sobre o ensino de números e operações e sobre resolução de problemas, e iniciamos nossas reflexões fazendo uma retrospectiva desse ensino a partir do antigo Ensino Primário (década de 1950). Segundo Nunes et al. (2009), nessa época, o ensino de Matemática era concebido por técnicas e instrumentos que os alunos utilizavam para solucionar problemas da "vida prática". Além disso, não 
existia nenhuma preocupação com questões relativas às ideias de números e com o sistema de numeração.

As atividades envolvendo as operações eram desenvolvidas com base em técnicas operatórias e na simples memorização dos resultados, ou seja, o conceito de operação e suas propriedades não eram discutidos com os alunos e a ideia de adição era ensinada de modo independente da ideia de subtração, assim como a multiplicação e a divisão.

Entretanto, a proposta de ensino apresentava aspectos interessantes com relação aos problemas que deveriam ser propostos aos alunos. Para Nunes et al. (2009), os problemas envolvendo números e operações deveriam apresentar dados da vida real, sem o uso de valores "absurdos"; ser familiares aos alunos, variados na forma e no conteúdo, e apresentar uma linguagem clara, precisa e acessivel a todos.

A partir dos anos de 1970, começaram a surgir, por parte dos educadores matemáticos, novas preocupações relacionadas ao ensino de Matemática. Referências ao conceito de números, às concepções do sistema de numeração decimal e aos conceitos de operações, foram sendo incorporados no ensino. Nesse mesmo período, os professores começaram a fazer uso do material dourado, com o intuito de mostrar aos alunos a compreensão das ideias de agrupamentos e trocas, assim como as noções básicas do sistema de numeração decimal: unidades, dezenas e centenas. No entanto, apesar de ter sido dada ênfase na compreensão das técnicas operatórias, estas ainda eram ensinadas a partir da representação dos números escritos, e o conceito de adição continuava desvinculado da subtração. Inclusive, algumas propostas sugeriam que a multiplicação fosse ensinada antes da subtração, pois "o conceito de multiplicação, na época, estava relacionado ao conceito de adição, sendo considerada somente como uma adição repetida, ou seja, de parcelas iguais". (NUNES et al., 2009, p. 12).

No início dos anos de 1980, começaram a ser discutidas no Brasil novas perspectivas para o ensino de números e operações. Essas discussões consideravam as experiências dos alunos com problemas numéricos. Na 
época foi observado que os alunos tinham mais afinidades com a aritmética oral (utilizada fora da sala de aula) do que com a aritmética escrita (utilizada em sala de aula). Surgia, então, como tendência renovadora, o movimento para o ensino da Matemática centrado na resolução de problemas que, por sua vez, constitui uma das bases para o ensino da Matemática atual. (MALDANER, 2011).

Essa tendência, ainda hoje, continua sendo apontada pelos PCN (BRASIL, 1997). Segundo o documento, o ponto de partida de uma atividade matemática não deve ser a definição dos conteúdos, mas a resolução de problemas que possa levar à construção desse conteúdo. Dessa forma, aparece, na Educação Matemática, uma metodologia de ensino que aponta para uma aprendizagem mais significativa pelo o aluno, assinalando para a necessidade de se percorrer pelo caminho da problematização (MENDONÇA, 1993).

O ensino e a aprendizagem através da resolução de problemas vão ao encontro do que Onuchic (1999) acredita. De acordo com a autora, o problema a ser proposto aos alunos deve possibilitar que utilizem seus conhecimentos prévios, de modo que sejam capazes de escolher o melhor procedimento ou estratégia a ser utilizado na resolução, para encontrar a solução e, assim, discutir e validar suas respostas.

Nesse sentido, Fayol (1996, p. 142) argumenta que “o primeiro trabalho que um sujeito confrontado com um problema [matemático] deve realizar consiste em construir uma representação da situação [...]". Essa representação requer dos alunos o reconhecimento das operações que envolvem a resolução do problema, pois, muitas vezes, as crianças sabem realizar a parte mecânica, isto é, fazer as contas, mas apresentam dificuldades no raciocinar, não entendendo o por quê de cada procedimento ou estratégia de resolução. (IMENES, 1999).

Com isso, os PCN (BRASIL, 1998) apontam que o tratamento que é dado ao estudo de números naturais nos anos finais do Ensino Fundamental, tais como a ausência de situações problema envolvendo números grandes, o desestímulo ao uso de procedimentos aritméticos, a 
ausência de um trabalho com estimativas e com cálculo mental, e o trabalho centrado nos algoritmos sem a compreensão dos conceitos e das relações envolvidas e da identificação de regularidades, são fatores que têm contribuído para que a aprendizagem do aluno acabe não se consolidando nesse nível de ensino.

Em relação ao ensino da Álgebra, Schliemann et al. (1998) defendem que o seu ensino seja introduzido, a partir dos anos iniciais do Ensino Fundamental, com problemas em que o aluno possa realizar comparações entre quantidades. Além disso, os autores consideram que as noções algébricas, quando introduzidas através de situações problemas, ajudam o aluno futuramente (em anos subsequentes) a entender melhor esse conteúdo, quando estará mais preparado para entender os conceitos algébricos em um nível de representação mais simbólica e abstrata.

Nesse sentido, os PCN (BRASIL, 1998) destacam que a Álgebra desempenha um importante papel para que o aluno desenvolva e exercite sua capacidade de abstração e de fazer generalizações, além de lhe permitir a aquisição de poderosas ferramentas para resolver problemas.

Os Princípios e Normas para Educação Escolar (NCTM, 2007) consideram que o ensino de Álgebra a partir de experiências anteriores com os números e suas propriedades, podem levar ao trabalho com símbolos e expressões, e com padrões, podem desenvolver a noção de função.

\section{A Resolução de Problemas como Metodologia de Ensino-Aprendizagem- Avaliação nas Aulas de Matemática}

A Metodologia de Ensino-Aprendizagem-Avaliação de Matemática através da Resolução de Problemas, tal como é apresentada por Allevato e Onuchic (2014), é uma metodologia diferente daquele trabalho em que regras de "como fazer" são privilegiadas. Trata-se de uma metodologia em que a construção de conhecimento se faz a partir de problemas (geradores) propostos como ponto de partida e orientação para o ensino e a aprendizagem de novos conceitos e novos conteúdos. 
Contudo, o que significa ensino-aprendizagem-avaliação de Matemática através de resolução de problemas?

A palavra composta ensino-aprendizagem-avaliação tem por objetivo “[...] expressar uma concepção em que o ensino, a aprendizagem e a avaliação devem ocorrer simultaneamente durante a construção do conhecimento de um determinado conteúdo pelo aluno através da resolução de problemas, com o professor sendo o mediador do processo". (ALLEVATO; ONUCHIC, 2014, p. 43).

Cai e Lester (2012) indicam que os problemas criam oportunidades de avaliação, no sentido de que o professor pode perceber "o que" e "como" os alunos estão aprendendo e onde estão encontrando dificuldades. Nessa perspectiva, Van de Walle (2009) tem destacado o potencial avaliativo da resolução de problemas, como fonte segura de valiosas informações que permitem ao professor, entre outras coisas, perceber a presença de concepções errôneas e de lacunas de conhecimento. Além disso, auxilia a planejar as próximas aulas, a ajudar seus alunos individualmente identificando suas necessidades específicas, a analisar seu progresso e a criar oportunidades de aprender. Os autores enfatizam, ainda, que a resolução de problemas possibilita conduzir o ensino partindo de onde o aluno está, e não de onde está o professor.

E o que vem ser um problema matemático?

Ao analisarmos a literatura relativa à resolução de problemas (DANTE, 1989; ONUCHIC, 1999; VAN de WALLE, 2009; ITACARAMBI, 2010) encontramos diferentes concepções sobre o que é um problema matemático, das quais optamos pela de Onuchic (1999, p. 215), que esclarece sua compreensão, afirmando que um problema "[...] é tudo aquilo que não se sabe fazer, mas que se está interessado em resolver”. A autora ainda esclarece que "[...] o problema não é um exercício no qual o aluno aplica de forma quase mecânica uma fórmula ou uma determinada técnica operatória" (ONUCHIC, 1999, p. 215), mas exige a elaboração de estratégias/procedimentos que possibilitem o aprimoramento do conhecimento durante a construção de sua resolução. 
Portanto, ensinar Matemática utilizando resolução de problemas não é uma tarefa fácil, pois não basta apresentar um problema e "ficar sentado", esperando que alguma mágica aconteça. Contudo, considerar a resolução de problemas como metodologia de ensino não significa dizer que existe uma forma rígida para desenvolvê-la nas aulas de Matemática. Allevato e Onuchic (2014) sugerem algumas etapas para que se possa colocar em prática e usufruir melhor dessa Metodologia no desenvolvimento de suas aulas: (1) preparação do problema; (2) leitura individual; (3) leitura em conjunto; (4) resolução do problema; (5) observar e incentivar; (6) registro das resoluções na lousa; (7) plenária; (8) busca do consenso; (9) formalização do conteúdo e (10) proposição e resolução de novos problemas.

Reiteramos que, nessa metodologia, os problemas são propostos aos alunos antes de lhes ter sido apresentado formalmente o conteúdo matemático mais apropriado à resolução do problema. Esse conteúdo deve estar de acordo com o ano de escolaridade em que se encontram os alunos e com os objetivos pretendidos pelo professor para aquela aula.

Dessa forma, o ensino-aprendizagem de um tópico matemático começa com um problema que expressa aspectos-chave desse tópico, e técnicas matemáticas devem ser desenvolvidas na busca de respostas razoáveis ao problema dado. A avaliação do crescimento dos alunos é feita continuamente, durante a resolução do problema. (ONUCHIC; ALLEVATO, 2011, p. 13).

E mais, essa metodologia contempla ações pedagógicas (interação entre alunos; entre alunos e professor) que promovem a busca por informação, investigação, experimentação e renovação do interesse e da motivação dos alunos, aspectos que serão apresentados na experiência relatada e analisada no presente artigo.

\section{O Cenário e a Metodologia Utilizada na Pesquisa}

Trata-se de uma pesquisa de natureza qualitativa, de modo que o pesquisador manteve contato direto com o ambiente da pesquisa, com os sujeitos envolvidos e com o problema que estava sendo estudado. Além 
disso, o pesquisador foi o principal instrumento, responsável pela organização e condução dos problemas desenvolvidos.

Utilizamos a observação participante e a análise documental, buscando identificar os aspectos relevantes, as dificuldades encontradas pelos alunos e suas atitudes perante a resolução dos problemas propostos e do conteúdo matemático em estudo. As observações foram registradas em um diário de campo. (HELDER, 2006; FIORENTINI; LORENZATO, 2009).

Os sujeitos participantes desta pesquisa foram 18 alunos do $5 .^{\circ}$ ano do Ensino Fundamental de uma escola pública estadual do Maranhão. O estudo desenvolvido teve como objetivo analisar e discutir estratégias/procedimentos utilizados pelos alunos na resolução de problemas envolvendo números e operações.

Durante a coleta dos dados, aplicamos três problemas, cujos objetivos, resoluções e discussões serão apresentados e discutidos na próxima seção. As resoluções dos problemas, escritas pelos alunos, e os registros das observações constituem os dados desta pesquisa. Para levar a efeito esses problemas, empregamos a metodologia de ensino-aprendizagem-avaliação de Matemática através da Resolução de Problemas. (ALLEVATO; ONUCHIC, 2014).

\section{Números e Operações: Problemas, Procedimentos e Análise das Resoluções}

Nesta seção descrevemos e analisamos as estratégias/procedimentos utilizados por alunos do $5 .^{\circ}$ ano do Ensino Fundamental para resolver problemas envolvendo números e operações. No momento da coleta dos dados, durante as aulas de Matemática, fizemos uso da metodologia de ensino-aprendizagem-avaliação através de resolução de problemas. Na análise, procuramos evidenciar as estratégias/procedimentos de resolução utilizados por esses alunos, suas dificuldades, e como a metodologia da resolução de problemas ajudou a superá-las. Também procuramos analisar as falas dos alunos, enquanto eles resolviam os problemas e durante as 
discussões na plenária, com o objetivo de (re)construir os conceitos de multiplicação e divisão e, consequentemente, sua aprendizagem. Nessa análise identificamos e descrevemos alguns aspectos que julgamos relevantes.

Vale ressaltar que durante a aplicação dos problemas utilizamos as etapas sugeridas por Allevato e Onuchic (2014), que serão ressaltadas em alguns momentos da análise.

O primeiro problema apresentado aos alunos foi:

Quando Joana entrou na sala de aula, a professora estava apagando o quadro, mas ela ainda pôde ver algo escrito, conforme mostra a figura. Qual é o húmero que foi apagado?

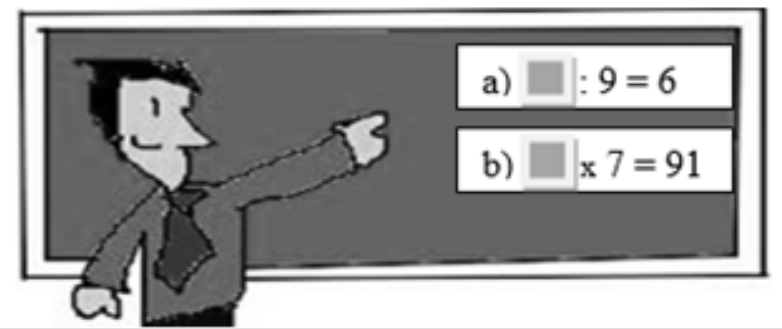

Fonte: Adaptação Itacarambi (2010)

Embora a multiplicação e a divisão ainda sejam ensinadas separadamente, na maioria dos programas curriculares, a multiplicação aparece sucedendo à divisão. No entanto, é importante ressaltar a importância de que a aprendizagem da divisão seja feita em estreita relação com a multiplicação e que a resolução de problemas de divisão pode ser feita utilizando conhecimentos em relação à multiplicação, conforme apontam Rocha, Rodrigues e Menino (2007), a fim de ajudar os estudantes a perceberem como elas estão relacionadas. Nesse sentido, o problema em questão tinha como objetivo construir ou (re)construir os conceitos de multiplicação e de divisão com os alunos, de modo que eles percebessem a relação existente entre essas duas operações, como sendo operações inversas. 
Para a resolução desse problema colocamos os alunos em duplas 5 . Após todos receberem uma folha com o enunciado, solicitamos que, individualmente, fizessem a leitura para a compreensão do problema. Após essa primeira leitura, pedimos que fizessem novamente a leitura, dessa vez em conjunto, ou seja, na dupla. Em seguida, perguntamos se haviam entendido o problema e o que era para ser feito. Questionamos cada uma das duplas, e os alunos responderam que haviam entendido; então, foi solicitado que eles começassem a resolver o problema.

\section{Ilustração: Alunos em dupla resolvendo o problema}

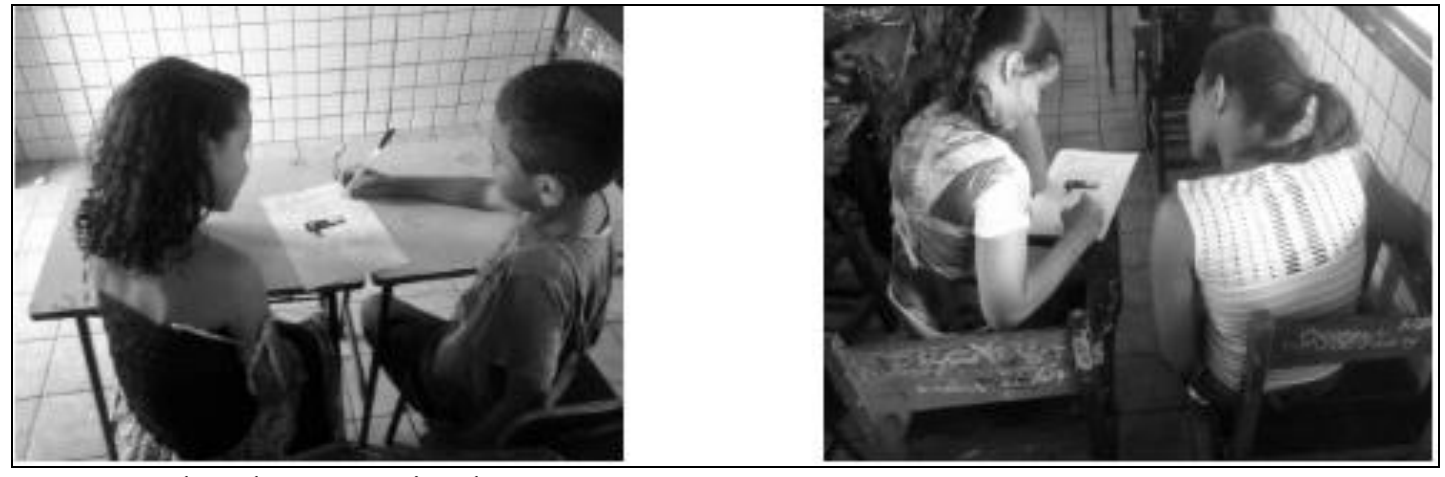

Fonte: Dados dos pesquisadores

A seguir, apresentamos alguns dos protocolos com as resoluções das duplas:

Figura 1: Resolução da dupla $D_{1}$

\begin{tabular}{|c|c|}
\hline $\begin{array}{l}\text { Procedimentos dos alunos: } \\
\text { a) Eu multipliquei }\end{array}$ & b) Eu deroidi 91ef \\
\hline nowre e allis bell. & e de incomtracia \\
\hline o rerultado $9 \times 6=54$ & revaletadog91/4 \\
\hline$\frac{541 \frac{9}{6}}{101 \frac{6}{6}}$ & $13 \times 7=91$. \\
\hline 111111 & 1111111111111 \\
\hline 111111 & 1111111111111 \\
\hline 111111 & 1111111111111 \\
\hline 111111 & 1111111111111 \\
\hline 111111 & 1111101111111 \\
\hline 111111 & 1111111111111 \\
\hline 111111 & 1111111111111 \\
\hline $\begin{array}{lllll}1 & 1 & 1 & 1 & 1 \\
1 & 1 & 1 & 1 & 1\end{array}$ & \\
\hline
\end{tabular}

Fonte: Dados dos pesquisadores.

${ }^{5}$ Para identificação das duplas utilizamos os códigos $\mathrm{D}_{1}$ (dupla 1), $\mathrm{D}_{2}$ (dupla 2) e assim sucessivamente. 
As resoluções apresentadas nos levam a crer que os alunos não tiveram dificuldade para resolver o problema, mas o que percebemos, em nossas observações durante a resolução, foi que, inicialmente, eles não sabiam como proceder para resolver, ou seja, os alunos expressaram dificuldade no entendimento do problema. Por isso, fez-se necessária uma intervenção do pesquisador que, nesse momento, solicitou aos alunos que observassem as operações envolvidas no problema e o que eles precisariam para encontrar o número (solução) que estava faltando.

Nunes (2014), em uma de suas pesquisas, fazendo uso da metodologia de ensino-aprendizagem-avaliação de Matemática através da resolução de problemas, diz que esse momento é crucial para o avanço do aluno em busca da resolução do problema. Nesse momento é necessário que o professor atenda os alunos colocando-se como interventor e questionador. Complementa que o professor deve

[...] acompanhar os alunos em suas explorações e ajudá-los quando necessário a resolver problemas secundários que podem surgir no decurso da resolução: notação, passagem da linguagem vernácula para linguagem matemática e, conceitos relacionados e técnicas operatórias a fim de possibilitar a continuidade do trabalho. (NUNES, 2014, p.74-75, grifo do autor).

A partir dessa intervenção, os alunos comentaram que ficou mais claro e que seria fácil encontrar a resposta. As duplas recorreram à multiplicação para solucionar o problema. Na resolução do item (a), a dupla $\mathrm{D}_{1}$ fez uso da multiplicação 9 × 6 e acreditamos que, para confirmar se a solução estava correta, recorreu à operação inversa, ou seja, à divisão de 54 por 9. Mesmo já tendo encontrado a solução correta para esse item, fizeram uso da adição repetida de parcelas iguais (usaram riscos) para confirmar se a quantidade estava de fato correta.

As estratégias/procedimentos utilizadas pela dupla $\left(\mathrm{D}_{1}\right)$, podem ser decorrentes do fato de que muitos professores dos anos iniciais ensinam o conceito de multiplicação como adição sucessiva de parcelas iguais; talvez 
por isso eles tenham utilizado esse procedimento de resolução, que é considerado válido.

A esse tipo de estratégia, Brocado, Delgado e Mendes (2007) chamam de Cálculo por contagem, em que os problemas são resolvidos recorrendo a expressões numéricas que incluam a operação adição. Acrescentam as autoras que neste nivel de multiplicação por contagem "[...] as crianças também recorrem a raciocínios e a expressões que incluem adição, só que, correspondem a adições sucessivas de parcelas iguais". (BROCADO; DELGADO; MENDES, 2007, p. 10).

Com relação ao item (b), a dupla também demonstrou certa facilidade, utilizando o mesmo procedimento do item anterior: primeiramente, fez a divisão de 91 por 7 e, em seguida, a operação inversa, isto é, a multiplicação. Como no item (a), recorreu ao uso dos riscos para confirmar se a solução estava correta, nesse caso, com o intuito de dividir, ou seja, usou a divisão com a ideia de repartir em partes iguais, conforme aponta Maldaner (2011).

A seguir, apresentamos resposta de outra dupla para o item a do problema:

Figura 2: Resolução da dupla $\mathrm{D}_{4}$

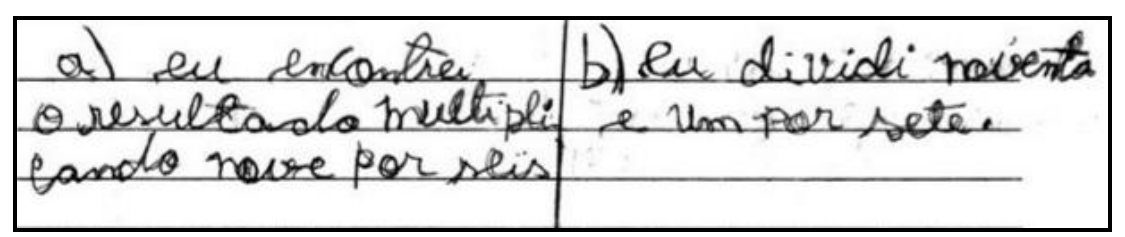

Fonte: Dados dos pesquisadores

$\mathrm{Na}$ resolução apresentada pela dupla $\left(\mathrm{D}_{4}\right)$, os alunos apenas apresentaram como procederam, ou seja, explicaram em linguagem corrente o que fizeram sem registrar a resolução em símbolos matemáticos. Mas pela explicação da dupla (durante a plenária), notamos que também pensou na multiplicação e, efetivamente, empregou as mesmas operações que a dupla anterior.

A terceira dupla, $\left(\mathrm{D}_{7}\right)$, apresentou uma solução mais objetiva tanto para o item (a), quanto para o item (b): 
Figura 3: Resolução da dupla $\mathbf{D}_{7}$

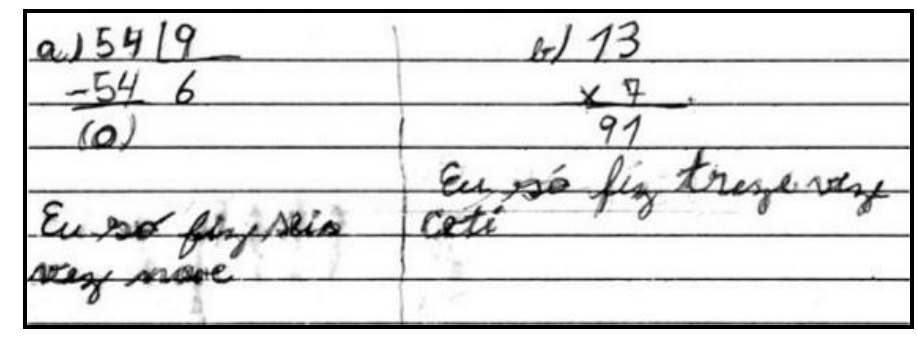

Fonte: Dados dos pesquisadores.

Percebemos claramente o uso da multiplicação quando eles comentam: "só fiz seis vezes nove" e "só fiz treze vezes sete", mesmo tendo indicado a divisão no item (a).

Ao fazer a exposição na lousa e durante a plenária - momento das discussões com toda a classe sobre as resoluções elaboradas - ficou notório que os alunos perceberam a relação existente entre essas duas operações.

No final, realizamos, em linguagem matemática, a formalização do conteúdo em estudo. Foi apresentada e discutida a multiplicação com números naturais da seguinte forma: (1) a multiplicação com a ideia de adição de parcelas iguais; (2) a ideia de proporcionalidade e (3) a ideia de formação retangular ou combinação. Além disso, foram exploradas três propriedades estruturais da multiplicação: a comutativa, a associativa e a distributiva da multiplicação em relação à adição.

Complementando, foi discutida a divisão com a ideia de repartir em partes iguais uma quantidade (partitiva) e com a ideia de calcular quantas vezes cabe uma quantidade em outra (cotitiva). Após essa formalização o pesquisador deu encaminhamento aos conceitos e procedimentos matemáticos que estavam sendo construídos, pois o mais importante nesse trabalho é ajudar os estudantes a compreenderem o que cada número, em uma expressão de multiplicação ou divisão, representa.

O segundo problema foi o seguinte:

Um livro de 100 páginas tem suas páginas numeradas de 1 a 100. Quantas folhas desse livro possuem o algarismo $\mathbf{5}$ em sua numeração?

Fonte: Itacarambi (2010). 
Neste problema, o objetivo era que os alunos percebessem nos números de 1 a 100 aqueles que fazem uso do algarismo 5 em sua formação, para que pudessem contar a quantidade de folhas em que eles estão inseridos. A seguir, apresentamos uma das resoluções que demonstram as estratégias/procedimentos utilizados pelas duplas:

Figura 4: Resolução da dupla $\mathrm{D}_{14}$

\begin{tabular}{l}
5 , $15,25,35,45,55,65,75,85,95$ \\
\hline confisindo de $5 \operatorname{lem} 5$ \\
\hline
\end{tabular}

Fonte: Dados dos Pesquisadores.

Após os alunos terem terminado de resolver o problema, questionamos: O problema foi fácil ou dificil de resolver? Todos os alunos responderam que havia sido mais fácil que o primeiro problema. Comentaram que não tiveram dificuldades para solucionar, pois tratava-se apenas de uma multiplicação por 5 e que, por isso, eles fizeram uma contagem de 5 em 5 para poder verificar quais as numerações.

No entanto, eles não se atentaram para a pergunta do problema que era saber o número de folhas que contém o algarismo 5 e não o número de páginas. Talvez por isso os alunos utilizaram uma sequência com números de 10 em 10 (Figura 4), esquecendo-se dos números compreendidos de 50 a 59, que também apresentam o algarismo 5. Dessa forma, os alunos não conseguiram contar corretamente o número de folhas que contém o algarismo 5 em suas páginas. Portanto, não chegaram à resposta correta: o livro tem 15 folhas com o algarismo 5 em sua numeração. São elas: as folhas em que os números aparecem em apenas um dos lados $(5,15,25,35,45$, $50,54,59,75,85,95)$, totalizando 11 folhas, e as folhas em que os números constam nos dois lados (51-52, 53-54, 55-56 e 57-58), totalizando 4 folhas.

Somente no momento das discussões sobre as resoluções, na plenária, e na formalização do conteúdo, e com a ajuda do pesquisador, os alunos perceberam de fato o que o problema estava solicitando.

Nossa experiência, enquanto professores, levou-nos a levantar a hipótese de que as dificuldades dos alunos na resolução de problemas 
podem estar relacionadas ao fato de a linguagem de seus enunciados ser pouco compreensivel, impedindo-os, de alguma forma, de compreender a situação apresentada. Essa ideia é reforçada na "fala" de Lopes, Pavanello e Franco:

[...] consideramos que o texto de um problema envolve não apenas a linguagem, mas elementos matemáticos e que, às vezes, a dificuldade na leitura está ligada a não compreensão desses elementos. É necessário termos sempre em conta que determinados conceitos, evidentes para o professor, nem sempre são claros para o aluno e, sem o seu conhecimento, não é possivel se avançar na solução de problemas escolares. (LOPES; PAVANELLO; FRANCO, 2010, p.179).

Assim, podemos deduzir que a dificuldade apresentada pelos alunos na linguagem desse problema não se deu apenas pelo pouco conhecimento que possuem da língua materna, mas também pelo pouco conhecimento do gênero textual de problemas matemáticos. Daí a importância da leitura individual e coletiva nas atividades sugeridas por Allevato e Onuchic (2014) ao apresentarem uma dinâmica para se trabalhar com a resolução de problemas.

Ao receberem o problema proposto pelo professor [pode ser também pelo aluno], cada aluno faz sua leitura, pois, assim, tem possibilidade de refletir, de colocar-se em contato com a linguagem matemática e desenvolver sua própria compreensão do problema proposto. (ALLEVATO; ONUCHIC, 2014, p. 45).

O terceiro e último problema (a seguir) apresentado aos alunos teve como objetivo discutir as primeiras noções de álgebra (equação) sem utilizar letras como x e y, normalmente utilizadas pelos professores na apresentação desse conteúdo a seus alunos. 


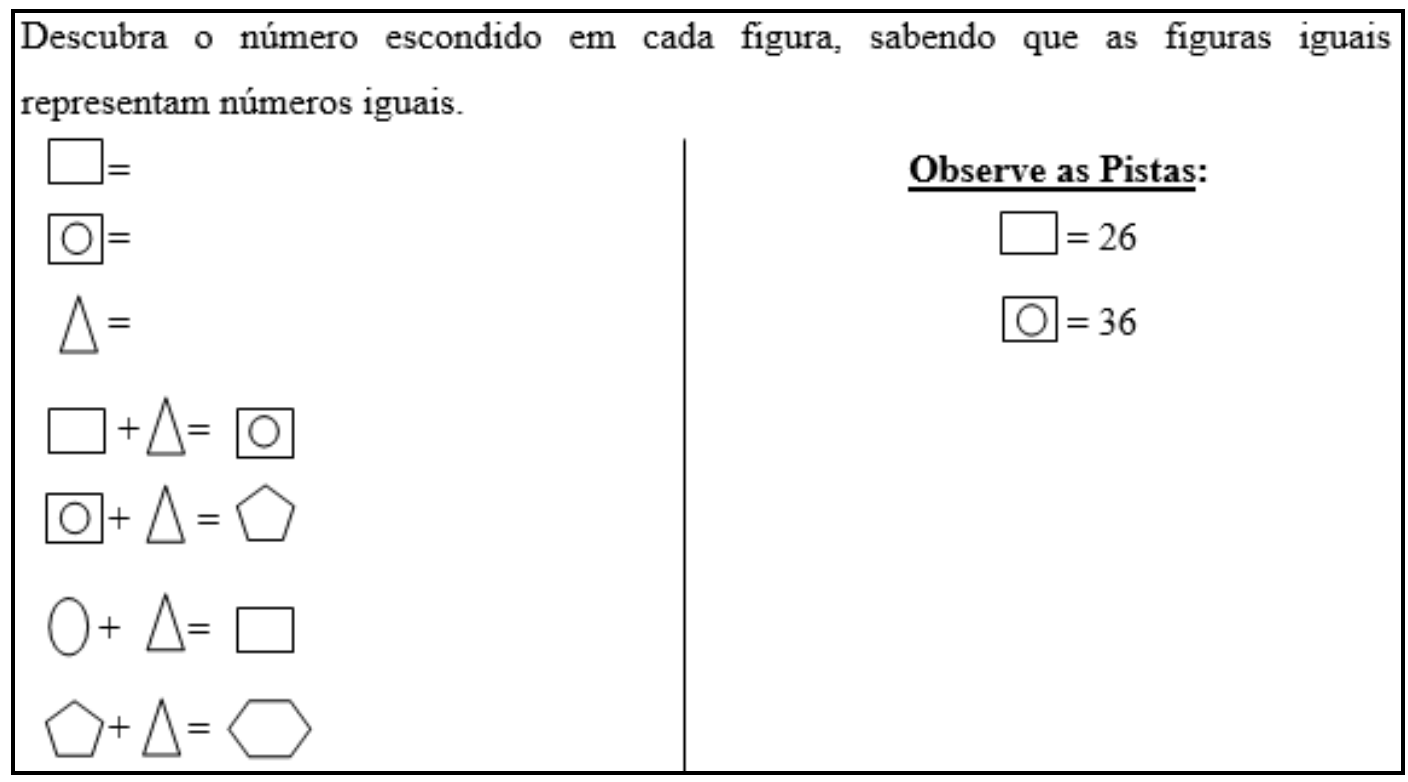

Fonte: Adaptação Itacarambi (2010).

Durante nossas observações, enquanto os alunos resolviam o problema, notamos que eles não tiveram dificuldade para solucioná-lo, demonstrando que haviam entendido o que estava sendo solicitado. No entanto, vale ressaltar que, da mesma forma que nos outros dois problemas, o pesquisador teve que ajudar os alunos no entendimento.

A seguir, apresentamos duas resoluções que ilustram os procedimentos utilizados pelas duplas.

Figura 7: Resolução das duplas $D_{1}$ e $D_{7}$, respectivamente

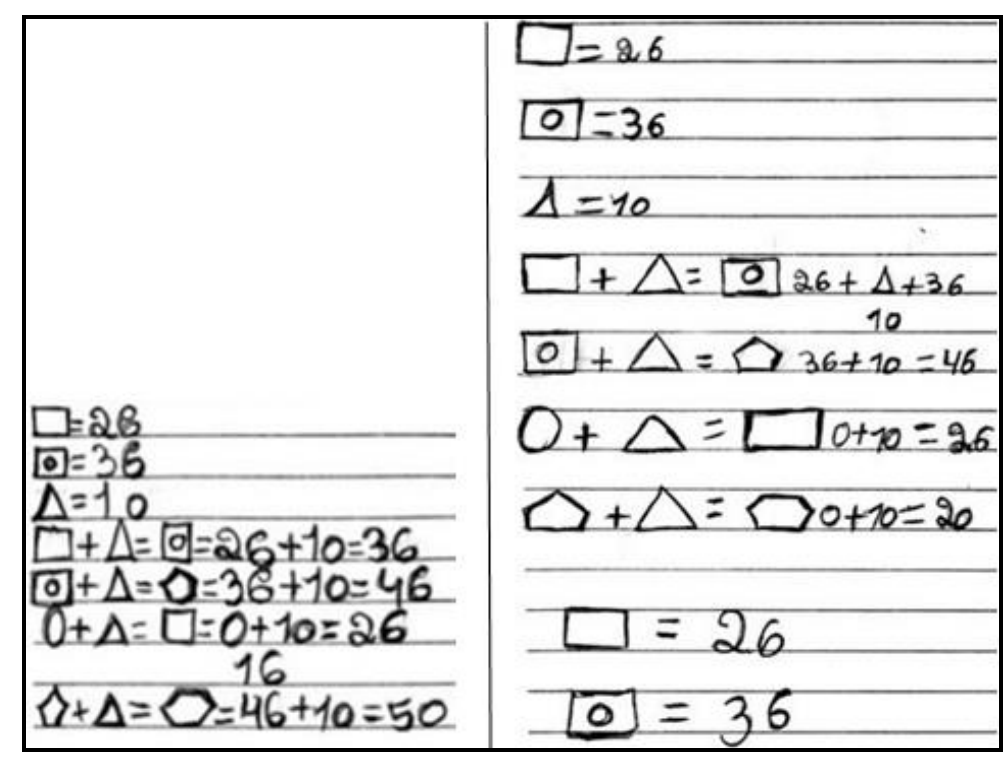

Fonte: Dados dos Pesquisadores. 
Durante a plenária, um dos alunos fez um comentário interessante, quando questionamos como haviam encontrado o valor $\triangle$ do (triângulo). o aluno comentou:

$D_{1}$ : - Professor, foi fácil encontrar o valor do triângulo! Como já sabíamos o valor das outras figuras, bastou tirar [subtrair] o menor valor do maior; o que sobrar é o valor do triângulo.

Nesse momento, percebemos que o aluno estava realizando o cálculo algébrico para obter o valor da figura em questão, sem utilizar letras, o que na maioria das vezes dificulta a compreensão dos alunos, principalmente nesse nivel de escolarização. De acordo com os documentos oficiais - PCN (BRASIL, 1998), a álgebra é um conteúdo que desenvolve a capacidade de abstração e generalização e é uma poderosa ferramenta para resolver problemas. Por esse motivo, é importante que os professores desenvolvam trabalhos que proponham situações em que o aluno seja capaz de construir noções algébricas através de atividades significativas e que tenham relações com o seu cotidiano.

\section{Considerações Finais}

Nosso objetivo, neste trabalho, foi explorar alguns aspectos relacionados aos conteúdos referentes ao bloco Números e Operações, apresentado pelos PCN. Fazendo uso da Resolução de Problemas como metodologia de Ensino-Aprendizagem, trabalhamos os conceitos básicos de Aritmética, sobretudo o de multiplicação e divisão, e as primeiras noções de Álgebra nos anos iniciais.

O trabalho nos revelou que, quando exploramos os conteúdos matemáticos através da resolução de problemas, o aluno percebe que é capaz de raciocinar por si mesmo, indo à busca de estratégias para a sua resolução. Entretanto, é necessário, para isso, que o professor esteja preparado para ser o mediador que conduz os alunos nessa "nova" iniciativa e para partir das resoluções que os alunos elaboram em direção à construção de novos conhecimentos. 
Apesar das dificuldades, nossa experiência foi muito rica, pois procuramos criar um ambiente de cooperação, de busca, de exploração e de descobertas entre os alunos, deixando claro que mais importante que obter a solução final para o problema, era a estratégia utilizada por eles para solucioná-los. Observamos que o trabalho desenvolvido em duplas possibilitou a mobilização de estratégias diferenciadas relativas à contagem e às operações de multiplicação e divisão. Além disso, os alunos tiveram a oportunidade de construir e compreender essas estratégias, que são conhecimentos metodológicos desse conteúdo, e compreender que as operações envolvidas nos problemas são inversas uma da outra, no momento em que as estratégias foram surgindo.

A proposta aqui discutida enfatiza a importância de se trabalhar com uma metodologia problematizadora, que exige do professor uma constante interação com seus alunos, bem como a interação entre os alunos. Além disso, a metodologia de ensino-aprendizagem-avaliação através da resolução de problemas destaca a importância de se desenvolver atividades em duplas e/ou em grupo, que desempenham um privilegiado papel nesse contexto, pois propiciam aos alunos a elaboração de justificativas e argumentações, além do contato com os diferentes caminhos utilizados, pelos colegas, para a resolução do problema, conforme indicação de Allevato e Onuchic (2014).

Asseveramos que, embora consideramos que seja importante desenvolver um trabalho pré-algébrico a partir dos anos iniciais, importa ressaltar que este estudo deve ser retomado sistematicamente a partir do $7 .^{\circ}$ ano para que os conceitos algébricos possam ser consolidados.

\section{Referências Bibliográficas}

ALLEVATO, N. S. G.; ONUCHIC, L. R. Ensino-Aprendizagem-Avaliação de Matemática: Por que através da Resolução de Problemas? In: ONUCHIC, L. R. et al. (Org.). Resolução de Problemas: teoria e prática. Jundiaí, SP: Paco Editorial, 2014. p. 35-52

BANDEIRA, E. Linguagem escrita em aulas de matemática: uma experiência em sala de aula. In: Anais do X EGEM - Encontro Gaúcho de Educação Matemática. Ijuí/RS: UNIJUÍ, 2009. 
BRASIL. Ministério da Educação e do Desporto. Secretaria de Educação. Parâmetros Curriculares Nacionais: Matemática. 3. ed. Brasília, DF: MEC, 1997.

- Ministério da Educação e do Desporto. Secretaria de Educação. Parâmetros Curriculares Nacionais: Matemática $1^{\circ}$ e $2^{\circ}$ ciclos - Brasília, DF: MEC, 1998.

BROCADO, J.; DELGADO, C.; MENDES, F. A multiplicação no contexto do sentido do número. In:_Desenvolvendo o sentido do número: perspectivas e exigências curriculares. Materiais para o professor do $1 .^{\circ}$ ciclo. Lisboa: APM, 2007, p. 9-18. V.II.

CAI, J.; LESTER, F. Por que o Ensino com Resolução de Problemas é Importante para a Aprendizagem do Aluno? Boletim GEPEM. Tradução: BASTOS, A. S. A. M.; AllEVATO, N. S. G. Rio de Janeiro, n. 60, 2012, p. 241-254.

COSTA, M. S. Discutindo o ensino de geometria com professores polivalentes. 2008. 145 f. Dissertação (Mestrado em Ensino de Ciências e Matemática) Universidade Cruzeiro do Sul, São Paulo, 2008.

COSTA, M. S.; ALLEVATO, N. S. G. AVALIAÇÃO: um processo integrado ao ensino e à aprendizagem de matemática através da resolução de problemas. ACTA SCIENTIAE - Revista de Ensino de Ciências e Matemática, Editora da ULBRA, v. 17, n. 2, p. 1-17, 2015.

CURI, E. A matemática e os professores dos anos iniciais. São Paulo, SP: Musa Editora, 2005.

DANTE, L. R. Didática da Resolução de Problemas de Matemática. São Paulo, SP: Ática, 1989.

FAYOL, M. A criança e o número: da contagem à resolução de problemas. Tradução: Rosana Severino de Leoni. Porto Alegre, RS: Artes Médicas, 1996.

FIORENTINI, D. Rumos da Educação Matemática: O professor e as mudanças didáticas e curriculares. II Seminário de Avaliação das Feiras Catarinenses de Matemática, 2001, Brusque. Rumos da Educação Matemática: O professor e as mudanças didáticas e curriculares, 2001. v. 1. p. 23-37.

FIORENTINI, D.; LORENZATO, S. Investigações em educação matemática: percursos teóricos e metodológicos. 3. ed. rev. Campinas, SP: Autores Associados, 2009.

HELDER, R. R. Como fazer análise documental. Porto: Universidade de Algarve, 2006. 
IMENES, L. M. Os números na história das civilizações. São Paulo, SP: Scipione, 1999.

ITACARAMBI, R. R. Resolução de Problemas: construção de uma metodologia (ensino fundamental I). São Paulo, SP: Editora Livraria da Física, 2010.

LOPES, S. E.; PAVANELLO, R. M.; FRANCO, V. S. Alunos do ensino fundamental e problemas escolares: Leitura e interpretação de enunciados. In: NOGUEIRA, C. M. I.; KATO, L. A.; BARROS, R. M. de O. (Org.). Teorias e práticas em educação matemática: aproximação da universidade com a sala de aula. Maringá, PR: Eduem, 2010. p. 175-188.

MALDANER, A. Educação matemática: fundamentos teóricos - práticos para professores dos anos iniciais. Porto Alegre, RS: Mediação, 2011.

MENDONÇA, M. C. D. Problematização: um caminho a ser percorrido em educação matemática. 1993. 307 f. Tese (Doutorado em Educação) Faculdade de Educação, Universidade de Campinas, Campinas, 1993.

NCTM. National Council of Teachers of Mathematics. Principios e normas para a matemática escolar. Lisboa: APM, 2007.

NUNES, T. et al. Introdução à Educação Matemática: números e operações numéricas. 2. ed. São Paulo, SP: Cortez, 2009.

NUNES, C. B. A Metodologia de Ensino-Aprendizagem-Avaliação de Matemática através da Resolução de Problemas: perspectivas à formação docente no contexto da sala de aula. In: REIS, M. J. E. et al (Orgs.). Educação e Desenvolvimento: diferentes olhares. Campinas, SP: Pontes Editores, 2014, p. 61-79. V.2. (Coleção Formação e Práxis Docente).

ONUCHIC, L. R. Ensino-Aprendizagem de Matemática através da Resolução de Problemas. In: BICUDO, M. A. V. (Org.). Pesquisa em Educação Matemática. São Paulo, SP: Editora UNESP, 1999. p. 199-220.

ONUCHIC, L. R.; ALlEVATO, N. S. G. Formação de Professores - Mudanças Urgentes na Licenciatura em Matemática. In: FROTA, M. C. R.; NASSER, L. (Org.). Educação matemática no ensino superior: pesquisas e debates. Recife. PE: SBEM, 2009.

Pesquisa em Resolução de Problemas: caminhos, avanços e novas perspectivas. BOLEMA - Boletim de Educação Matemática, UNESP - Rio Claro, v 25, p. 73-98, 2011.

PIRES, C. M. C. Educação Matemática: conversas com professoras dos anos iniciais. São Paulo, SP: Zé-Zapt Editora, 2012.

ROCHA, I.; RODRIGUES, M.; MENINO, H. A divisão no contexto do sentido do número. In: Equipe do Projeto Desenvolvendo o Sentido do Número: 
perspectivas e exigências curriculares. Desenvolvendo o sentido do número, materiais para o professor do $1^{\circ}$ ciclo, vol. II. Lisboa: APM, 2007.

SCHLIEMANN, A. D. et al. Solving Algebra Problems before Algebra Instruction. Paper presented at the Second Early Algebra Meeting, Tufts University/UMass-Dartmouth, 1998.

VAN DE WALLE, J. A. Matemática no ensino fundamental: formação de professores e aplicação em sala de aula. Trad. Paulo Henrique Colonese. 6. ed. Porto Alegre, RS: Artmed, 2009.

Recebido: 15 de março de 2017

Aceito: 28 de agosto de 2017

Publicado: 19 de setembro de 2017 